\title{
Retraction: Cirujano, F. Ionic liquids vs. Microporous Solids as Reusable Reaction Media for the Catalytic C-H Functionalization of Indoles with Alcohols. In Proceedings of the 22nd International Electronic Conference on Synthetic Organic Chemistry, 15 November-15 December 2019; Sciforum Electronic Conference Series, doi: 10.3390/ecsoc-22-05655
}

\author{
Francisco Cirujano ${ }^{1}$, ECOSC-22 Editorial Office ${ }^{2}$ \\ 1 Centre for Surface Chemistry and Catalysis, Department of Microbial and Molecular Systems, KU Leuven- \\ University of Leuven, Leuven Chem\&Tech, Celestijnenlaan 200F, Post Box 2461, 3001 Heverlee, Belgium \\ 2 MDPI, St. Alban-Anlage 66, 4052 Basel, Switzerland
}

\begin{abstract}
At the request of the author, the paper [1] is retracted. It was previously published in Green Chemistry [2] and the conference covers only original work. We apologize to readers for any inconvenience caused. MDPI is a member of the Committee on Publication Ethics (COPE) and takes seriously the responsibility to enforce strict ethical policies and standards. The published article [1] is retracted and shall be marked accordingly.
\end{abstract}

Reference

1. Cirujano, F. Ionic liquids vs. microporous solids as reusable reaction media for the catalytic $\mathrm{C}-\mathrm{H}$ functionalization of indoles with alcohols. In Proceedings of The 22nd International Electronic Conference on Synthetic Organic Chemistry, 15 November-15 December 2019; Sciforum Electronic Conference Series, doi: 10.3390/ecsoc-22-05655

2. Cirujano, F.; Stalpaert, M; De Vos, D.E. Ionic liquids vs. microporous solids as reusable reaction media for the catalytic $\mathrm{C}-\mathrm{H}$ functionalization of indoles with alcohols. Green Chem. 2018, 20, 2481-2485.

(C) 2018 by the authors. Licensee MDPI, Basel, Switzerland. This article is an open access article distributed under the terms and conditions of the Creative Commons Attribution (CC BY) license (http://creativecommons.org/licenses/by/4.0/). 